\title{
Article \\ Chlorhexidine Mucoadhesive Buccal Tablets: The Impact of Formulation Design on Drug Delivery and Release Kinetics Using Conventional and Novel Dissolution Methods
}

\author{
Enas Al-Ani ${ }^{1, *(\mathbb{D})}$, David Hill ${ }^{1,2, *}$ and Khalid Doudin ${ }^{3}(\mathbb{D}$ \\ 1 Research Institute in Healthcare Science, Faculty of Science and Engineering, University of Wolverhampton, \\ Wolverhampton WV1 1LY, UK \\ 2 School of Biology, Chemistry and Forensic Science, Faculty of Science and Engineering, \\ University of Wolverhampton, Wolverhampton WV1 1LY, UK \\ 3 Department of Chemistry, The University of Sheffield, Sheffield S10 2TN, UK; K.Doudin@sheffield.ac.uk \\ * Correspondence: e.al-ani2@wlv.ac.uk (E.A.-A.); D.Hill@wlv.ac.uk (D.H.); Tel.: +44-1902-32-5876 (E.A.-A.)
}

Citation: Al-Ani, E.; Hill, D.; Doudin, K. Chlorhexidine Mucoadhesive Buccal Tablets: The Impact of Formulation Design on Drug Delivery and Release Kinetics Using Conventional and Novel Dissolution Methods. Pharmaceuticals 2021, 14, 493. https://doi.org/10.3390/ ph14060493

Received: 22 April 2021

Accepted: 17 May 2021

Published: 23 May 2021

Publisher's Note: MDPI stays neutral with regard to jurisdictional claims in published maps and institutional affiliations.

Copyright: (c) 2021 by the authors. Licensee MDPI, Basel, Switzerland. This article is an open access article distributed under the terms and conditions of the Creative Commons Attribution (CC BY) license (https:// creativecommons.org/licenses/by/ $4.0 /)$.

\begin{abstract}
Oropharyngeal candidiasis (OPC) is a mucosal infection caused by Candida spp., and it is common among the immunocompromised. This condition is mainly treated using oral antifungals. Chlorhexidine (CHD) is a fungicidal and is available as a mouth wash and oral gel. It is used as an adjuvant in the treatment of OPC due to the low residence time of the current formulations. In this study, its activity was tested against C. albicans biofilm and biocompatibility with the HEK293 human cell line. Then, it was formulated as mucoadhesive hydrogel buccal tablets to extend its activity. Different ratios of hydroxypropyl methylcellulose (HPMC), poloxamer 407 (P407), and three different types of polyols were used to prepare the tablets, which were then investigated for their physicochemical properties, ex vivo mucoadhesion, drug release profiles, and the kinetics of drug release. The release was performed using Apparatus I and a controlled flow rate (CFR) method. The results show that CHD is biocompatible and effective against Candida biofilm at a concentration of $20 \mu \mathrm{g} / \mathrm{mL}$. No drug excipient interaction was observed through differential scanning calorimetry (DSC) and Fourier-transform infrared spectroscopy (FTIR). The increase in P407 and polyol ratios showed a decrease in the swelling index and an increase in CHD in vitro release. The release of $\mathrm{CHD}$ from the selected formulations was $86-92 \%$. The results suggest that chlorhexidine tablets are a possible candidate for the treatment of oropharyngeal candidiasis.
\end{abstract}

Keywords: chlorhexidine; mucoadhesive; hydrogel; buccal; release kinetics; flow rate; Candida albicans; cytocompatibility

\section{Introduction}

Oropharyngeal candidiasis (OPC) is a common opportunistic infection in immunocompromised patients, caused by Candida spp. and, most commonly, C. albicans. The annual estimated number of OPC cases is 10 million globally. The treatment of OPC is hampered by the limited number of antifungal drugs available, drug resistance, drug-drug interaction, and adverse effects. Uncontrolled OPC could result in systemic candidiasis, which has a mortality rate of $30-50 \%$ [1,2].

Systemic antifungals are the most effective treatment for OPC, specifically azoles (fluconazole, itraconazole, miconazole, clotrimazole) and polyene (nystatin or amphotericin B deoxycholate) [3]. Antifungals cause a variety of side effects, including gastrointestinal disturbances, nephrotoxicity, and hepatotoxicity [4]. Furthermore, azoles exhibit drug-drug interaction by inhibiting the CYP3A4 isoenzyme, thus, increasing the risk of immunosuppressant toxicity due to their low therapeutic index of the latter [5]. Another drawback of treatment with azoles is that Candida can develop resistance due to their fungistatic activity rather than fungicidal [6]. Caspofungin is recommended as a second line treatment for 
patients refractory to azoles and polyenes [7]. It is administered as an intravenous infusion due to its poor intestinal absorption and short half-life, thus, limiting its administration to hospitalized patients only [8]. Furthermore, immunocompromised patients with OPC developed systemic candidiasis after they had received nystatin, which failed to control the infection [9]

Cellulose derivatives, chitosan, and polyacrylic acid derivatives are the main hydrogelforming polymers used to prepare mucoadhesive buccal dosage forms due to their mucoadhesive properties, biocompatibility, cost-effectiveness, and availability [10-12]. Several hydrogel-forming polymers have been previously investigated for the treatment of OPC during the past decades. For instance, chitosan, pectin, and HPMC were formulated as miconazole buccal films for the delivery of miconazole nitrate [13]. Fluconazole oral strips were prepared with HPMC and polyacrylic acid derivatives [10]. Both formulations showed more than $80 \%$ drug release in the first hour. A CHD buccal tablet prepared with HPMC, carbopol, and lactose sustained the release for up to eight hours [14]. Chitosan and sodium alginate buccal film successfully extended the release of CHD up to three hours [15]. Clotrimazole and nystatin were loaded individually into hydroxypropyl cellulose and polyethylene oxide films. The release of the drug was maintained for up to eight hours [16].

To combat drug resistance and overcome systemic side effects, chlorhexidine (CHD) was selected in this study to be formulated as a local controlled drug delivery. CHD is available as a $0.2 \% w / v$ mouthwash, a $0.2 \% w / v$ oral spray, and a $1 \% w / v$ dental gel. However, they all have a short retention time in the oral cavity. As CHD cannot be absorbed from the gastrointestinal tract, it has no systemic side effects [17], and to date, there are no documented reports of acquired resistance to CHD [18]. Antifungal activity is achieved through the binding of CHD cations to the anionic surface charge of the fungal cell wall, leading to a decrease in adhesion capacity, the loss of structural integrity, and finally, disruption of the cell wall [19]. Consequently, there is an urgent need for a new approach to the localized, prolonged delivery of antifungal agents for enhanced OPC therapy.

The aim of this study was to prepare safe and effective chlorhexidine mucoadhesive hydrogel buccal tablets containing HPMC and P407 polymers. The tablets were designed to control the release of CHD over two hours to minimize patient intolerance that can result from a prolonged application time and lead to withdrawal from treatment [20]. Drug release studies were conducted using dissolution Apparatus 1 and a newly-designed dissolution method to investigate the release of CHD using a controlled rate of dissolution media at $1 \mathrm{~mL} / \mathrm{min}$ to mimic drug release in the oral cavity, which is performed by saliva. The normal salivary flow rate is $\geq 1 \mathrm{~mL} / \mathrm{min}$ with a maximum value of $7 \mathrm{~mL} / \mathrm{min}[21,22]$. Despite there being several marketed buccal tablets, there is no compendial standard available to mimic drug release in the oral cavity.

\section{Results and Discussion}

\subsection{Antifungal Activity of CHD}

The minimum inhibitory concentration (MIC) and minimum biocidal concentration (MBC) of CHD against C. albicans planktonic cells were 2.5 and $5 \mu \mathrm{g} / \mathrm{mL}$, respectively. The effect of CHD was investigated for two hours against both immature and mature biofilms. The investigation was performed to establish the concentration of CHD against $C$. albicans biofilms to be incorporated in the tablets. The viability of CHD-treated biofilms was measured using an XTT reduction assay. CHD showed nearly a 100\% loss of mitochondrial activity on a 4 -h biofilm at a concentration of $\geq 10 \mu \mathrm{g} / \mathrm{mL}$, and the viability was around $16 \%$ at a concentration of $5 \mu \mathrm{g} / \mathrm{mL}$ (Figure $1 \mathrm{a}$ ). The effectiveness of CHD decreased with an increase in the maturity of the biofilm (Figure 1b). Nearly a 100\% suppression of metabolic activity was achieved at a concentration of $\geq 40 \mu \mathrm{g} / \mathrm{mL}$ with a significant reduction to $15 \%$ and $26 \%$ at 20 and $10 \mu \mathrm{g} / \mathrm{mL}$ of CHD, respectively. 


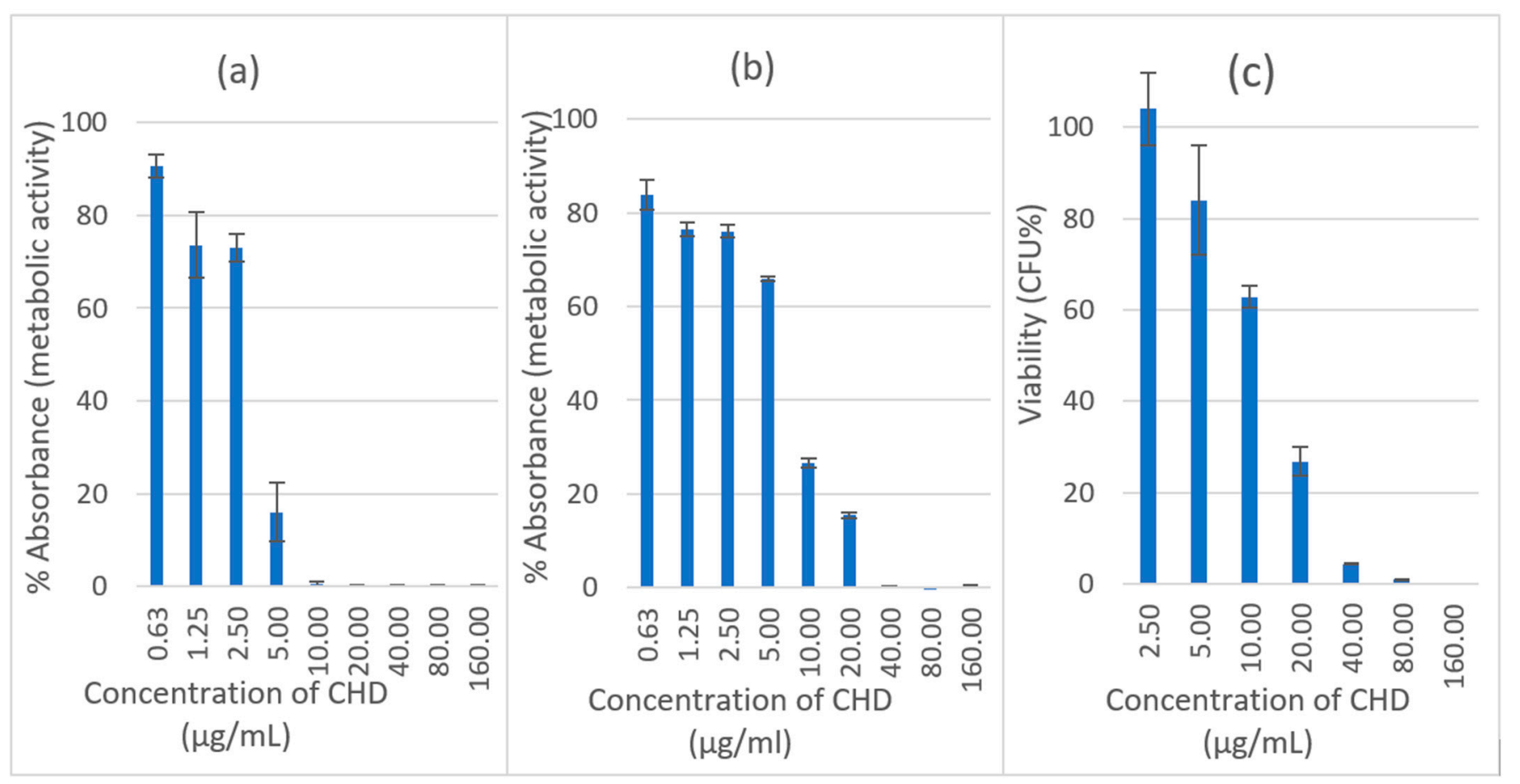

Figure 1. Effect of CHD on initial C. albicans biofilm, (a) $4 \mathrm{~h}$ and (b) $24 \mathrm{~h}$ using XTT assay. Data are expressed as mean percentages $\pm \mathrm{SE}, n=12$. (c) Biofilm recovery (viable count) of $\mathrm{C}$. albicans after treatment with $\mathrm{CHD}$ at $30^{\circ} \mathrm{C}$, Data are expressed as mean percentages $\pm \mathrm{SE}, n=3$.

The sensitivity of planktonic cells to antifungals is higher than that of biofilm cells. This is because there is a more uniform distribution of the drug in planktonic cell culture media, whereas a concentration gradient of extrinsic and intrinsic material results from the uneven thickness and cell density in the biofilm [23]. The increase in the resistance of a pathogenic strain of $C$. albicans biofilm with an increase in its maturity and using CHD has previously been documented. The MIC increased from 16 to $256 \mu \mathrm{g} / \mathrm{mL}$ for $\sim 4-\mathrm{h}$ and $72-\mathrm{h}$ biofilms, respectively. This increase in resistance might be due to extracellular material, genetic or biochemical changes in the cells [24].

\subsection{Biofilm Recovery}

The recovery of the biofilm was measured using a viable count of 24-h biofilms treated with CHD. It was undertaken to determine the number of living cells that were capable of reproduction. The recorded viability was $4 \%$ at a concentration of $\geq 40 \mu \mathrm{g} / \mathrm{mL}$ compared to $0.5 \%$ for the XTT assay (Figure 1c). The recovery was $26.8 \%$ and $62.8 \%$ compared to $15.4 \%$ and $26.6 \%$ mitochondrial activity at 20 and $10 \mu \mathrm{g} / \mathrm{mL}$, respectively. This means that XTT overestimates the killing effect at certain concentrations, which might be attributed to the low sensitivity of XTT towards slow-growing candida cells that are affected by drug treatment [25].

\subsection{Cytocompatibility}

Neutral red is a weak basic dye that penetrates cells by diffusion and accumulates in the lysosomes, staining them red due to their low $\mathrm{pH}$ compared to the cytoplasm. In living healthy cells, the $\mathrm{pH}$ gradient is maintained. However, when a cell dies, lysosomes are not able to retain the dye due to the loss of the $\mathrm{pH}$ gradient [26]. NR assay was used to measure the lysosomal activity of human cells and, consequently, facilitate the estimation of the cytocompatibility of the drugs. CHD is considered to be cytotoxic against HEK293 cells at concentrations of 80 and $160 \mu \mathrm{g} / \mathrm{mL}$ (Figure 2). The retained lysosomal activity was less than $20 \%$. Drugs are considered cytotoxic when cell viability is $\leq 70 \%$ [27]. At a concentration of $\leq 20 \mu \mathrm{g} / \mathrm{mL}$ of $\mathrm{CHD}$, the preserved viability was approximately $100 \%$. 


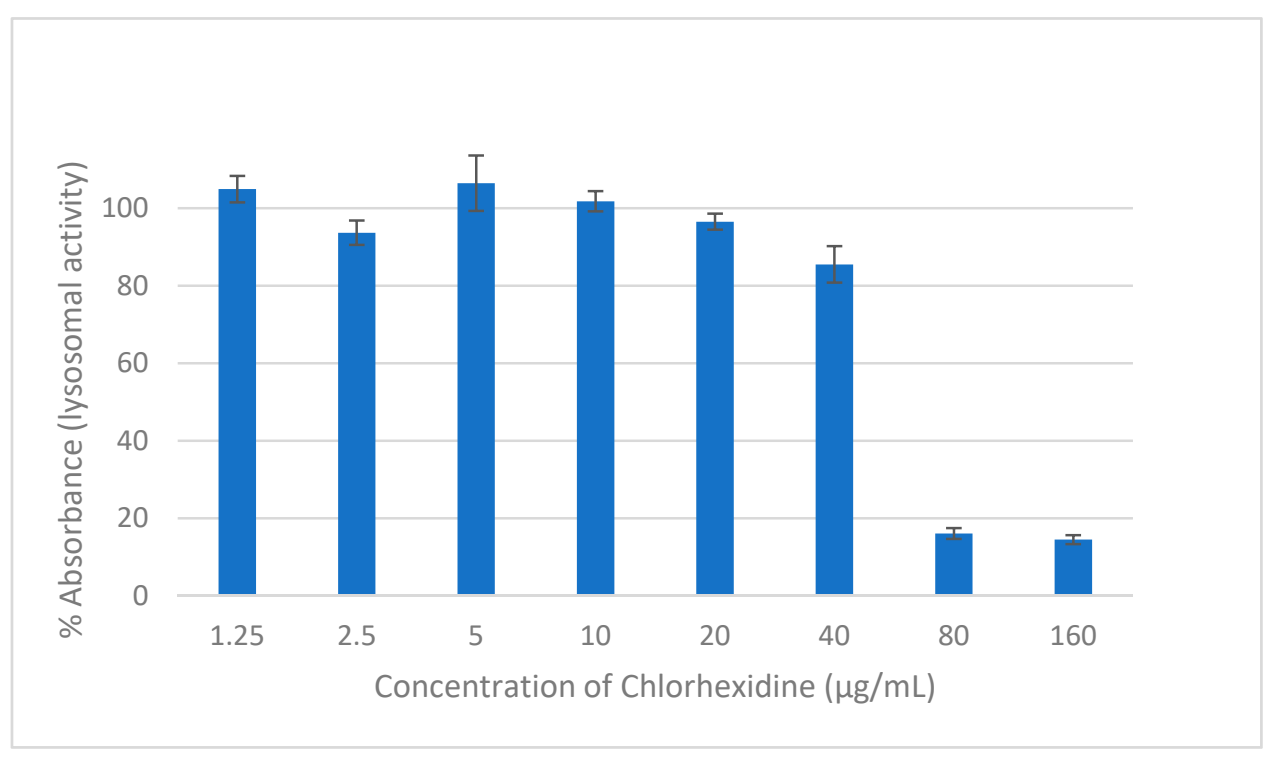

Figure 2. The effect on the viability of HEK293 cells of two hours of exposure to different concentrations of CHD measured using NR assay. Data are expressed as mean percentages $\pm \mathrm{SE}, n=9$.

Based on the microbiological investigations, a concentration of $20 \mu \mathrm{g} / \mathrm{mL}$ of CHD was effective in killing planktonic cells and 4-h biofilm cells and $26.8 \%$ of the mature biofilm survived. This concentration is considered cytocompatible with HEK293 cells; they showed a viability of $96.5 \%$. Consequently, a concentration of $20 \mu \mathrm{g} / \mathrm{mL}$ of CHD was chosen for the formulation of the tablets due to its efficacy and safety. Moreover, upon repeated application, new biofilm formation will be inhibited, and mature biofilms will be diminished and eradicated over time.

\subsection{Characterisation of Powder Blends and Granules}

In the current study, hydrogel-forming polymers were used to formulate a mucoadhesive buccal tablet to prolong and control the release of CHD in the oral cavity. Hydrogels comprise a three-dimensional, crosslinked structure of hydrophilic polymers, which retain water and form porous structures [12]. They are used as drug delivery systems as they resemble natural tissue, in that they retain large quantities of water $[28,29]$. Three groups of CHD hydrogel mucoadhesive buccal tablets were prepared based on the type of polyol: sorbitol, mannitol, and xylitol. Each group was prepared with two different ratios of polymers (P407 to HPMC) and two different ratios of polyols (Table 1). The ratio of the polymers was chosen on the basis of our previous investigation [30]. Granules were prepared using melt granulation; both the excipients and CHD are thermostable as demonstrated by DSC analysis (see Supplementary Materials, Figure S5)

Table 1. Composition of CHD mucoadhesive buccal tablets.

\begin{tabular}{|c|c|c|c|c|c|c|c|c|c|c|c|c|}
\hline \multirow{2}{*}{ Ingredients } & S1 & $\mathbf{S} 2$ & S3 & $\mathrm{S} 4$ & M1 & M2 & M3 & M4 & X1 & $\mathrm{X} 2$ & $\mathrm{X} 3$ & $X 4$ \\
\hline & \multicolumn{12}{|c|}{ Quantity mg/tab } \\
\hline CHD & 2.5 & 2.5 & 2.5 & 2.5 & 2.5 & 2.5 & 2.5 & 2.5 & 2.5 & 2.5 & 2.5 & 2.5 \\
\hline P407 & 14 & 14 & 21 & 21 & 14 & 14 & 21 & 21 & 14 & 14 & 21 & 21 \\
\hline HPMC & 14 & 14 & 7 & 7 & 14 & 14 & 7 & 7 & 14 & 14 & 7 & 7 \\
\hline Sorbitol & 7 & 14 & 7 & 14 & - & - & - & - & - & - & - & - \\
\hline Mannitol & - & - & - & - & 7 & 14 & 7 & 14 & - & - & - & - \\
\hline Xylitol & - & - & - & - & - & - & - & - & 7 & 14 & 7 & 14 \\
\hline Weight & 37.5 & 44.5 & 37.5 & 44.5 & 37.5 & 44.5 & 37.5 & 44.5 & 37.5 & 44.5 & 37.5 & 44.5 \\
\hline $\begin{array}{c}\text { Ratio (code) } \\
\text { P407/HPMC/Polyol }\end{array}$ & $2: 2: 1$ & $2: 2: 2$ & 3:1:1 & $3: 1: 2$ & $2: 2: 1$ & $2: 2: 2$ & $3: 1: 1$ & $3: 1: 2$ & $2: 2: 1$ & $2: 2: 2$ & 3:1:1 & $3: 1: 2$ \\
\hline
\end{tabular}


HPMC is a non-ionic hydrophilic polymer with mucoadhesive and hydrogel-forming properties. It has widely been investigated in buccal drug delivery and is included in marketed products [31]. P407 is a non-ionic co-polymer of polyethylene oxide and polypropylene oxide that has a thermo-reversible, hydrogel-forming ability. It has mucoadhesive properties and gels at a concentration of $>20 \%$ at $25{ }^{\circ} \mathrm{C}$ [32]. It has wide application in drug delivery, for example, in oral solutions; suspensions; inhalers; and parenteral, ophthalmic, and topical formulations. Its mucoadhesive potential has been utilized in rectal and ophthalmic preparations [33]. In the current study, it was formulated into tablet dosage forms with HPMC to control the release of CHD by taking advantage of its surfactant and hydrogel-forming properties to improve the hydration of the tablet and maintain the three dimensional structure [34].

Polyols have a sweet taste and provoke a cooling sensation resulting from their negative heat of dissolution. They have a low glycemic index and are non-cariogenic [35]. They are frequently used in oral dosage forms, such as orally disintegrating tablets, lozenges, chewable tablets, chewing gum toothpaste [36], and as moisturizers in artificial saliva [37]. Sorbitol, mannitol, and xylitol are sugar alcohols, which do not promote or reduce tooth decay [38]. Sorbitol, mannitol, and xylitol were added to improve the taste perception, especially because they have non-cariogenic properties.

Flow through an orifice is proposed as a better method to measure powder flowability based on the British and United States Pharmacopoeias. The mass flow of the powders and granules was investigated by measuring the flow through a funnel with an orifice size of $10 \mathrm{~mm}$ diameter $\mathrm{f}$. Powder blends failed to pass through the orifice. However, all granules successfully passed through the orifice (Table 2), and formulations with a higher ratio of P407 showed an improvement in mass flow. Based on the compressibility index, the flowability of powder blends varied from 'poor' to 'very very poor'. The flowability of granules displayed a remarkable improvement, ranging from 'passable' to 'good' (Table 2) [39].

Table 2. Flow rate $(\mathrm{g} / \mathrm{sec})$ of granules through a $10 \mathrm{~mm}$ orifice size. Data are expressed as mean $\pm \mathrm{SD}$, $n=3$.

\begin{tabular}{cccccc}
\hline Formulation & \multicolumn{2}{c}{ Powder Blends } & Granules \\
\hline \multicolumn{7}{c}{ CI } \\
M1 & $30.81 \pm 0.87$ & $p$ & $20.72 \pm 0.61$ & $\mathrm{~F}$ & $4.73 \pm 0.12$ \\
M2 & $37.20 \pm 0.073$ & VP & $20.57 \pm 2.05$ & $\mathrm{~F}$ & $4.73 \pm 0.12$ \\
M3 & $40.07 \pm 0.66$ & VVP & $12.50 \pm 0.00$ & $\mathrm{G}$ & $6.30 \pm 0.00$ \\
M4 & $29.60 \pm 0.37$ & $p$ & $11.81 \pm 0.16$ & $\mathrm{G}$ & $6.30 \pm 0.00$ \\
X1 & $39.11 \pm 1.32$ & VVP & $20.86 \pm 1.04$ & $\mathrm{~F}$ & $4.43 \pm 0.15$ \\
X2 & $34.97 \pm 4.23$ & VP & $22.72 \pm 1.09$ & PA & $4.53 \pm 0.12$ \\
X3 & $35.43 \pm 3.81$ & VP & $21.79 \pm 1.43$ & PA & $4.67 \pm 0.23$ \\
X4 & $39.47 \pm 2.70$ & VVP & $21.81 \pm 1.42$ & PA & $6.00 \pm 0.30$ \\
S1 & $39.50 \pm 2.09$ & VVP & $22.76 \pm 1.05$ & PA & $4.53 \pm 0.15$ \\
S2 & $39.87 \pm 1.66$ & VVP & $22.32 \pm 1.74$ & PA & $4.80 \pm 0.20$ \\
S3 & $39.32 \pm 1.65$ & VVP & $27.46 \pm 1.37$ & $p$ & $6.83 \pm 0.23$ \\
S4 & $41.55 \pm 3.57$ & VVP & $22.88 \pm 1.26$ & PA & $6.10 \pm 0.00$ \\
\hline G good, F fair, PA passable, P poor, VP very poor, VVP very very poor. &
\end{tabular}

\subsubsection{Physical Properties of the Tablets}

Table 3 presents the friability and tensile strength results. The tablets showed an acceptable level of friability of less than $1 \%$. Within each group of formulations, there was no significant difference in tensile strength $(p>0.05)$. However, the only reported difference between the three groups was between (S1and X1) and (S1and M1) $(p<0.05)$, with S1 having a higher tensile strength. Sorbitol displayed plastic deformation and has good binding properties [40]. 
Table 3. Friability and tensile strength of CHD mucoadhesive buccal tablets.

\begin{tabular}{lcc}
\hline & $\begin{array}{c}\text { Tensile Strength (MPa) } \\
\boldsymbol{n}=\mathbf{1 0} \pm \mathbf{S D}\end{array}$ & Friability (\%) \\
\hline S1 & $1.03 \pm 0.29$ & 0.00 \\
S2 & $0.80 \pm 0.23$ & 0.07 \\
S3 & $0.90 \pm 0.28$ & 0.17 \\
S4 & $0.85 \pm 0.14$ & 0.01 \\
M1 & $0.63 \pm 0.35$ & 0.19 \\
M2 & $0.94 \pm 0.16$ & 0.08 \\
M3 & $0.96 \pm 0.22$ & 0.33 \\
M4 & $0.88 \pm 0.18$ & 0.26 \\
X1 & $0.37 \pm 0.06$ & 0.26 \\
X2 & $0.67 \pm 0.11$ & 0.10 \\
X3 & $0.56 \pm 0.17$ & 0.23 \\
X4 & $0.74 \pm 0.21$ & 0.08 \\
\hline
\end{tabular}

\subsubsection{Swelling Index (SI)}

The swelling index of the tablets was directly proportional to the HPMC ratio and inversely proportional to the $\mathrm{P} 407$ and polyol ratios. This is attributed to the higher molecular weight of HPMC compared to P407 and polyols. The decrease in SI with an increase in the polyols ratio is explained by their higher solubility [41]. There is a significant difference in SI $(p<0.5)$ within each group of formulations. However, the SI of S4, M4, and $X 4$ was 3 with no significant difference $(p>0.5)$, which might indicate that the type of sugar has no impact on the swelling of the formulations. The swelling profile for all formulations is presented in the Supplementary Materials (Figure S2).

\subsubsection{Determination of Ex Vivo Residence Time}

The disintegration apparatus was used to test the residence time of the adhered tablets to the tissue. The frequency of the moving arm of the disintegration apparatus was 30 cycles per minute, which is equivalent to compendial disintegration testing for tablets. All tested tablets successfully adhered to the chicken crop (pouch), which was repeatedly immersed in the aqueous media for two hours. This represents the ideal residence time of the tablets in the buccal cavity. Figure 3 shows the residue of S4, M4, and X4 tablets at the end of the test. The mucoadhesive property is attributed to the presence of HPMC and P407 [42,43].

\subsubsection{In Vitro Dissolution and Erosion Studies}

Despite there being several marketed buccal tablets, there is no compendial standard for drug release in the oral cavity. Two methods of dissolution were used to investigate the release of CHD: (i) Apparatus 1, using $500 \mathrm{~mL}$ of dissolution media: this method was used to test the effect of a large volume of dissolution media on drug release, and to investigate the effect of fluid consumption while the table is adhering to the oral mucosa. (ii) drug release based on a controlled flow rate (CFR) of $1 \mathrm{~mL} / \mathrm{min}$ to mimic the salivary flow rate in the oral cavity. The normal salivary flow rate is $\geq 1 \mathrm{~mL} / \mathrm{min}$ with a maximum value of $7 \mathrm{~mL} / \mathrm{min}[21,22]$. Drug release based on a controlled flow rate has previously been investigated elsewhere [44-47].

Dissolution results are presented in Figure 4: Apparatus I (a, b, and c) and CFR (d, e, and f). Using Apparatus I, all formulations showed a release of $>60 \%$. However, release using the CFR method for the same formulations was affected by the ratio of polymers. The release of CHD from the tablets with equal amounts of HPMC and P407 (S1,S2,M1,M2,X1, and $\mathrm{X} 2$ ) was around $30 \%$. However, the release was $>60 \%$ from tablets with a HPMC to P407 ratio of 1:3 (S3,S4,M3,M4,X3, and X4). 


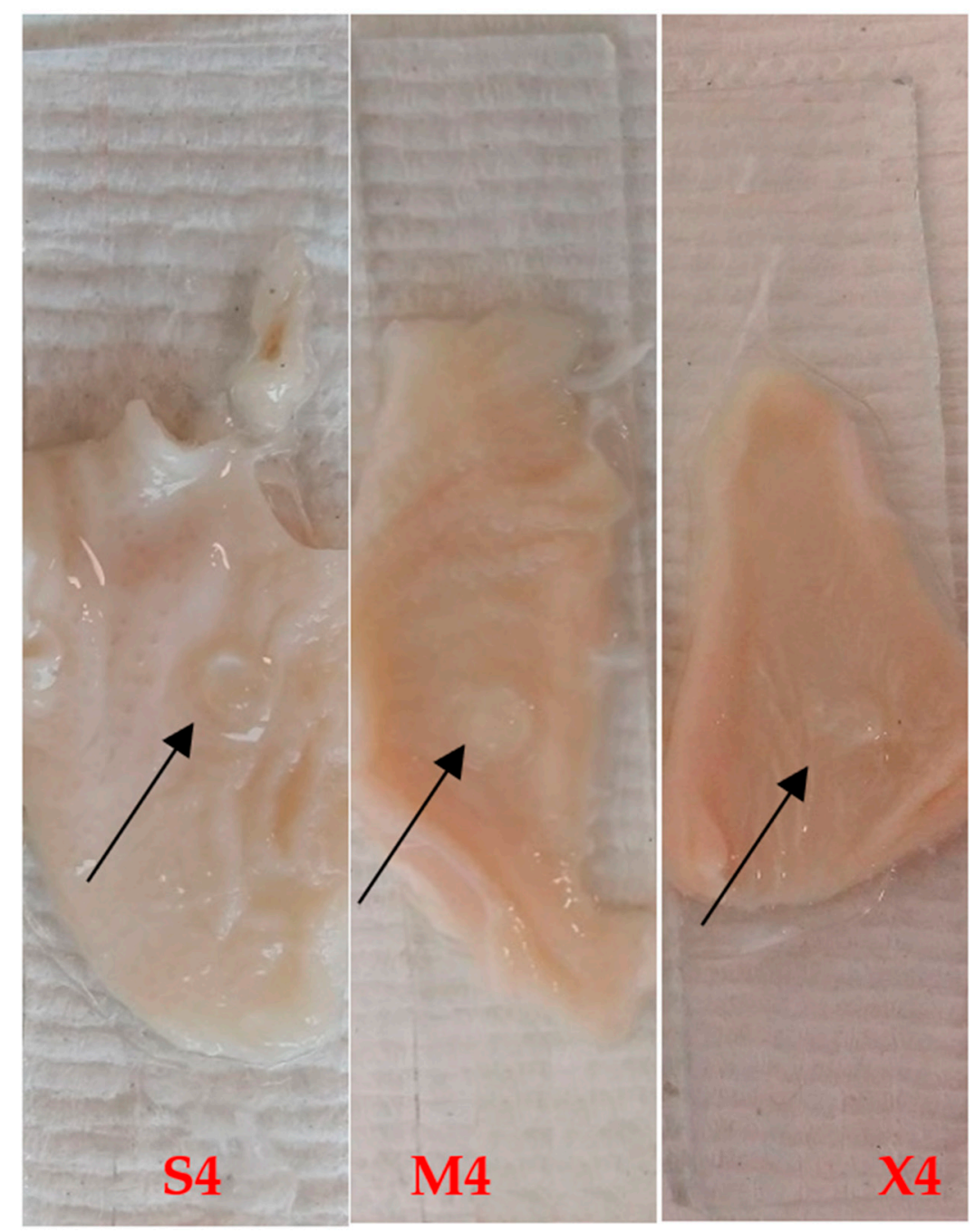

Figure 3. S4, M4, and X4 after two-hour ex vivo mucoadhesion using disintegration apparatus. The arrows show the hydrogel tablet after two hours.

The release of CHD using Apparatus 1 was 93\% for M4 and X4 and $87 \%$ for S4 and, using CFR, the release was 87,90 , and $89 \%$ for S4, M4, and X4, respectively. An unpaired Ttest showed no significant difference between the two methods $(p>0.05)$. This is attributed to the higher hydrophilicity of these formulations, which resulted in a faster hydration of the matrices and rapid formation of the interlocked gel layer in S4, M4, and X4. The gel layer prevents the rapid ingress of water and subsequently controls drug release from the hydrogel matrix [48]. The increase in the ratio of sorbitol, mannitol, and xylitol improved CHD release from S3 to S4 due to their solubility, which was enhanced by the surfactant activity of P407 [33,49], and there was a similar improvement for mannitol and xylitol correspondent formulations. P407 improved the release of CHD from the HPMC matrix, and this is attributed to the absence of interaction between the polymers, CHD, or polyols in S4, M4, and X4 formulations [42]. This was confirmed by the DSC and FTIR results, which showed no interaction between CHD and the excipients of the formulations (see Supplementary Materials, Figures S5 and S6).

The non-cumulative $\mathrm{CHD}$ released from $\mathrm{S} 4, \mathrm{M} 4$, and $\mathrm{X} 4$ using a constant flow rate are presented in Figure 5. CHD release showed a slight burst of release at a concentration of $22-23 \mu \mathrm{g} / \mathrm{mL}$ at the $10-\mathrm{min}$ point, followed by a concentration range of $16-21 \mu \mathrm{g} / \mathrm{mL}$ for all three formulations. Data relating to non-cumulative release from other formulations are available in the Supplementary Materials (Figure S6). Based on the cytotoxicity and antifungal assays, this range of concentration is considered safe and effective, and upon 
reapplication of the tablets, CHD can be used for the treatment of OPC. However, further in vivo investigation needs to be conducted.
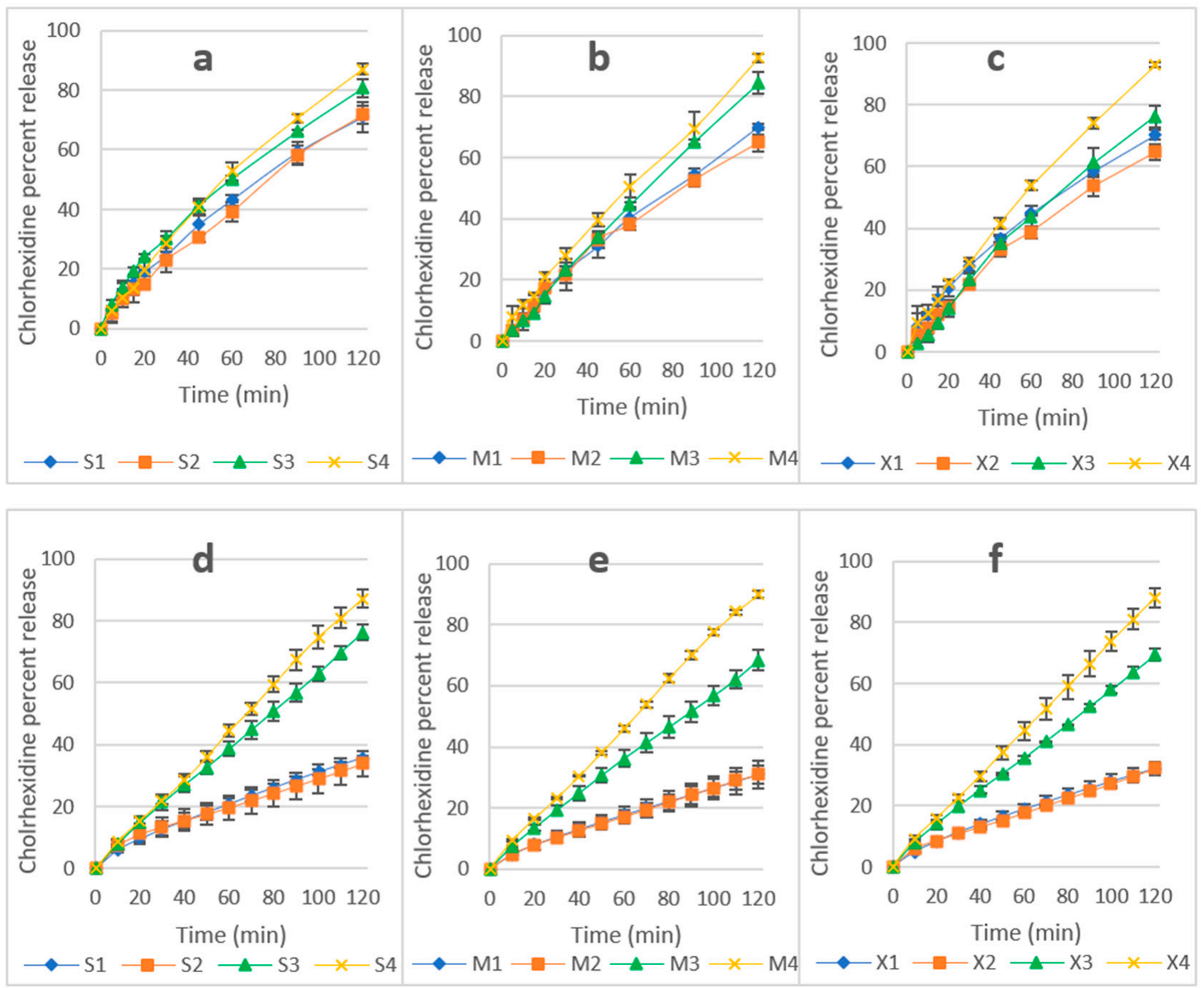

Figure 4. (a-c) CHD release using Apparatus I (a-sorbitol, b-mannitol, and $\mathbf{c}-x y$ litol formulations). (d-f) CHD release using CFR (d-sorbitol, e-mannitol, and $\mathbf{f}-x y$ litol). Data are expressed as mean percentages $\pm \mathrm{SD}, n=3$.

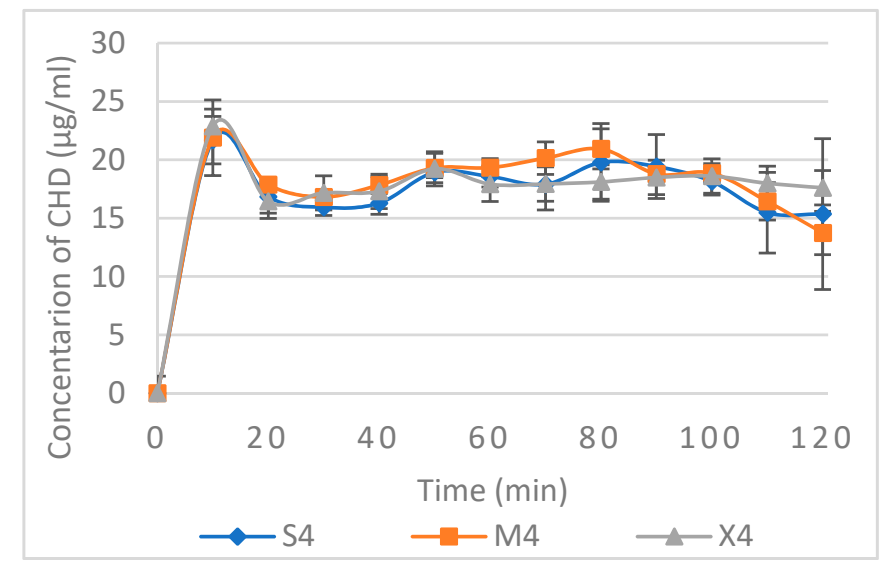

Figure 5. Non-cumulative CHD release from S4, M4, and X4 using CFR $1 \mathrm{~mL} / \mathrm{min}$. Data are expressed as mean concentration $\pm \mathrm{SD}, n=3$. 
In order to understand the mechanism of drug release, tablet erosion (E\%) was investigated. This was determined after two-hour dissolution using the CFR method (Table 4). The $\mathrm{E} \%$ increased with an increase in the hydrophilicity of the formulation (attained by increasing the ratio of P407 and sorbitol, mannitol, or xylitol). Furthermore, there was no significant difference in any of the formulations between the percentage of drug release and $\mathrm{E} \%(p>0.5)$, which indicated that erosion played a significant role in CHD release. SEM micrographs show the microporous structure of the hydrated tablets (Figure S3); pores would permit water penetration and, consequently, drug release by diffusion [50]. This is confirmed by the swelling of the tablets (Figure S2 Supplementary Materials), which swelled up to 3-4.5 of their origional weight. However, it is not known if the release was mainly controlled by erosion, diffusion, or both. All formulations developed a porous structure when examined under scanning electron microscopy (Supplementary Materials, Figure S3).

Table 4. $\mathrm{E} \%$ and $\mathrm{CHD} \%$ release using the CFR method at the two-hour point $( \pm \mathrm{SD}, n=3)$.

\begin{tabular}{cccc}
\hline Formulations & \% E (2 h) & \% CHD Release $\mathbf{( 2 ~ h ) ~}$ & Paired $\boldsymbol{t}$ Test \\
\hline S1 & $36.87 \pm 5.88$ & $35.57 \pm 0.76$ & \\
S2 & $39.70 \pm 9.04$ & $33.87 \pm 4.16$ & \\
S3 & $70.84 \pm 10.17$ & $76.14 \pm 2.52$ & \\
S4 & $88.15 \pm 2.62$ & $87.18 \pm 2.99$ & \\
M1 & $28.43 \pm 3.12$ & $30.97 \pm 4.58$ & No significant \\
M2 & $28.86 \pm 1.69$ & $30.92 \pm 2.92$ & difference \\
M3 & $69.50 \pm 5.65$ & $68.41 \pm 3.40$ & \\
M4 & $84.63 \pm 4.07$ & $89.81 \pm 1.22$ & \\
X1 & $30.41 \pm 5.25$ & $32.14 \pm 2.35$ & \\
X2 & $36.44 \pm 2.54$ & $32.31 \pm 1.00$ & \\
X3 & $70.41 \pm 1.67$ & $69.35 \pm 2.03$ & \\
X4 & $87.21 \pm 5.67$ & $88.05 \pm 3.26$ & \\
\hline
\end{tabular}

\subsection{Kinetics of Drug Release}

CHD release data were fitted to zero order, first order, Higuchi, Hixon-Crowell, Korsmeyer-Peppas (KP, the power law) and Hopfenberg (HP) models. DDsolver was used to obtain the non-linear fitting coefficients of determination $\mathrm{R}^{2}$. MSC was obtained for KP, $\mathrm{HP}$, and zero order due to their comparable and high $\mathrm{R}^{2}$ (Table 5). The higher the MSC, the better the fit, and a value greater than 2-3 indicates a good fit [51]. The values of $\mathrm{R}^{2}$ for first order, Higuchi, and Hixson-Crowell models are listed in the Supplementary Materials (Table S2).

In the KP model, the mechanism of drug release is explained by the value of the exponent $n$. This value for the cylindrical tablet is as follows; $0.45>n>0.89$ indicating anomalous, 0.89 is case II transport, and $>0.89$ is supercase II [52]. The latter means that drug release is controlled by swelling and relaxation or erosion [53]. The $n$ value for CHD tablets lies between approximately 0.7-1.0.

The exponent $n$ in HP model reflects the geometry of the releasing system. The values $1,1.5,2$, and 3 represent a slab, a half sphere, a cylinder, and a sphere, respectively [54]. DDsolver linearization was performed by starting with $n=1$ and steadily increasing it to achieve the best linearity [51]. Consequently, a higher $n$ value indicated the fit was not valid (Table 5). For instance, the $n$ value for S1 obtained using Apparatus 1 was 181.2, and this shape is not valid according to the HP model [54]. 
Table 5. Drug release kinetics using different fitting models for CHD formulation (Apparatus 1 dissolution) and CFR $1 \mathrm{~mL} / \mathrm{min}$.

\begin{tabular}{cccccccccc}
\hline & \multicolumn{3}{c}{ ZERO } & & KP & & \multicolumn{3}{c}{ HP } \\
\hline & & $\boldsymbol{R}^{\mathbf{2}}$ & MSC & $\mathbf{R}^{\mathbf{2}}$ & MSC & $\boldsymbol{n}$ & $\boldsymbol{R}^{\mathbf{2}}$ & MSC & $\boldsymbol{n}$ \\
\hline & S1 & 0.978 & 3.3 & 0.994 & 4.6 & 0.750 & 0.992 & & 181.8 \\
& S2 & 0.992 & 4.3 & 0.995 & 4.2 & 0.848 & 0.997 & 4.6 & 2.2 \\
& S3 & 0.979 & 3.4 & 0.998 & 4.6 & 0.708 & 0.991 & & 248.6 \\
& S4 & 0.985 & 3.6 & 0.995 & 4.7 & 0.822 & 0.996 & 4.9 & 2 \\
& M1 & 0.988 & 4.1 & 0.995 & 4.4 & 0.856 & 0.996 & & 6.8 \\
Apparatus 1 & M2 & 0.975 & 3.2 & 0.985 & 3.4 & 0.819 & 0.991 & & 291.1 \\
& M3 & 0.996 & 5.1 & 0.992 & 4.4 & 1.047 & 0.997 & 5.5 & 1.1 \\
& M4 & 0.993 & 4.2 & 0.994 & 4.2 & 0.825 & 0.993 & 4.4 & 1.4 \\
& X1 & 0.970 & 2.9 & 0.997 & 5.0 & 0.694 & 0.983 & & 1344.8 \\
& X2 & 0.980 & 3.4 & 0.991 & 3.9 & 0.826 & 0.995 & & 99.5 \\
& X3 & 0.988 & 3.9 & 0.991 & 3.9 & 1.058 & 0.996 & 5.1 & 1.7 \\
& X4 & 0.992 & 4.3 & 0.995 & 4.5 & 0.815 & 0.995 & 4.8 & 1.6 \\
\hline & S1 & 0.984 & 3.9 & 0.998 & 5.7 & 0.756 & 0.980 & & 425.7 \\
& S2 & 0.975 & 3.1 & 0.993 & 4.3 & 0.677 & 0.951 & & 605.6 \\
& S3 & 0.998 & 5.9 & 0.999 & 6.9 & 0.941 & 0.998 & 6.0 & 1.2 \\
& S4 & 0.998 & 5.9 & 0.998 & 5.4 & 0.992 & 0.998 & 5.8 & 1.0 \\
CFR 1 & M1 & 0.991 & 4.2 & 0.999 & 6.9 & 0.783 & 0.990 & & 671.8 \\
& M2 & 0.992 & 4.6 & 0.998 & 5.6 & 0.813 & 0.989 & & 177.3 \\
& M3 & 0.998 & 6.0 & 1.000 & 7.7 & 0.895 & 0.999 & 6.2 & 1.4 \\
& M4 & 0.999 & 6.4 & 0.999 & 5.6 & 0.962 & 0.999 & 6.5 & 1.1 \\
& X1 & 0.988 & 3.9 & 0.999 & 6.7 & 0.766 & 0.988 & & 495.6 \\
& X2 & 0.992 & 4.2 & 0.996 & 4.7 & 0.792 & 0.986 & & 438.6 \\
& X3 & 0.998 & 6.0 & 0.999 & 6.6 & 0.901 & 0.998 & 6.0 & 1.3 \\
& X4 & 0.999 & 6.6 & 0.999 & 6.4 & 0.956 & 0.999 & 6.5 & 1.0 \\
\hline
\end{tabular}

Taking into consideration the R2 and MSC (Table 5), the release from S2, S4, M3, M4, $\mathrm{X} 3$, and X4 using Apparatus 1 are best fitted with the HP model, which indicates erosioncontrolled drug release. The sorbitol formulations with a higher sugar ratio showed erosion control due to the solubility of sorbitol being $2 \mathrm{mg} / \mathrm{mL}$ compared to 0.63 and $0.18 \mathrm{mg} / \mathrm{mL}$ for xylitol and mannitol, respectively. For the xylitol and mannitol formulations, the erosion was attributed to the high P407 ratio. It is not fully known why the S3 formulation did not follow the same mechanism. The $n$ values for erosion controlled formulations was approaching 2 due to the full exposure of the tablet to the dissolution media reflecting its cylindrical shape [54]. The release from S4, M4, and X4 using CFR was mainly controlled by erosion, and it followed zero order drug release and HP model with the $n$ value closer to 1. This is because of the release being performed from one surface due to the adherence of the tablet to the sample holder. This might explain the low SI of these formulations, among others (Figure S2 Supplementary Materials), which is attributed to continuous erosion during the swelling process. All other formulations show a better fit with KP model, which indicates the involvement of diffusion, swelling and erosion, or polymer relaxation. The erosion of the tablet is affected by rotation speed, and this explains the higher drug release and why more formulations fit to HP model using Apparatus 1 compared to CFR [55].

\subsection{Dissolution Efficiency (DE\%)}

DE was used to compare the two methods of dissolution. DE for CHD release using Apparatus 1 was higher for all formulations, and it was double for S1, S2, M1, M2, X1, and X2 using Apparatus 1 compared to the CFR method. This is attributed to the effect of rotational speed and a higher volume of dissolution media. In contrast, the difference was much less for $\mathrm{S4}, \mathrm{M} 4$, and $\mathrm{X} 4$, with a value of $5 \%, 3 \%$, and $7 \%$, respectively, which is attributed to its faster hydration and the formation of an interlocked gel layer. (Table 6). 
Table 6. DE of CHD release using Apparatus I and CFR methods. Data are expressed as mean percentages $\pm \mathrm{SD}, n=3$.

\begin{tabular}{ccc}
\hline Formulations & Apparatus I & CFR \\
\hline S1 & $41.12 \pm 2.46$ & $20.25 \pm 1.48$ \\
S2 & $39.12 \pm 2.72$ & $19.54 \pm 3.46$ \\
S3 & $47.34 \pm 0.73$ & $38.78 \pm 2.06$ \\
S4 & $48.89 \pm 1.11$ & $44.44 \pm 1.92$ \\
M1 & $38.02 \pm 2.49$ & $17.19 \pm 2.71$ \\
M2 & $36.85 \pm 1.30$ & $16.94 \pm 2.39$ \\
M3 & $43.48 \pm 0.63$ & $35.31 \pm 2.39$ \\
M4 & $49.03 \pm 2.82$ & $46.34 \pm 0.54$ \\
X1 & $42.10 \pm 0.46$ & $18.16 \pm 1.57$ \\
X2 & $37.19 \pm 1.68$ & $17.57 \pm 0.43$ \\
X3 & $41.52 \pm 2.79$ & $35.74 \pm 0.68$ \\
X4 & $51.40 \pm 0.46$ & $44.55 \pm 2.34$ \\
\hline
\end{tabular}

Drug release studies for S4, M4, and X4 showed the best release, and they were least effected by the different methods of drug release.

\section{Materials and Methods}

\subsection{Materials}

The following materials were purchased from Sigma Aldrich, UK: sabauroud dextrose agar (SDA), Muller Hinton broth (MHB), chlorhexidine diacetate salt hydrate (CHD), RPMI-1640 dry powder (RPMI), 3-(n-Morpholino) propane sulfonic acid (MOPS), acetone Dulbecco's Modified Eagle's Medium (DMEM), a high glucose powder, bovine serum (FBS), L-Glutamine solution (200 mM), Antibiotic-Antimycotic Solution (10,000 U penicillin, $10 \mathrm{mg}$ streptomycin, and $25 \mu \mathrm{g}$ amphotericin B per ml), Neutral red (3-amino-7-dimethylamino2-methyl-phenazine hydrochloride Poloxamer 407 (P407), and sorbitol. The following materials were purchased from Alpha Easer, UK: 2,3-bis(2-methoxy-4-nitro-5-sulfophenyl)2H-tetrazolium-5-carboxanilide (XTT), menadione (2-Methyl-1,4-Naphthoquinone or vitamin K3), and glutaraldehyde and magnesium stearate sorbitol. The following materials were kindly provided by Roquette Company, UK. Xylitol (Xylisorb XTAB 240) and mannitol (Pearlitol 200 SD)., UK: Methocel ${ }^{\mathrm{TM}}$ F4M premium hydroxypropyl methylcellulose was kindly provided by Dow-Colorcon Company, UK.

\subsection{Methods}

\subsubsection{Antifungal Assays}

Minimum Inhibitory Concentration (MIC) and Minimum Biocidal Concentration (MBC)

C. albicans ATCC 10,321 were grown on a SDA plate and incubated at $30^{\circ} \mathrm{C}$ for $18-24 \mathrm{~h}$. Colonies of $C$. albicans were then transferred to MHB, and the turbidity was adjusted to 0.5 McFarland standard solution. MIC was measured using the broth tube dilution method. CHD was dissolved and serially double-diluted from 10 to $0.087 \mu \mathrm{g} / \mathrm{mL}$ in MHB to a final volume of $5 \mathrm{~mL}$. Then, $200 \mu \mathrm{L}$ of the inoculum was transferred to each test tube and incubated at $30^{\circ} \mathrm{C}$ for $24 \mathrm{~h}$. The MBC was determined by inoculating SDA plates with broth from MIC tubes that showed no visible growth and incubated at $30^{\circ} \mathrm{C}$ for $24-48 \mathrm{~h}$. The test was performed in triplicate.

\section{C. albicans Biofilm Formation and Treatment}

RPMI was prepared as instructed by the manufacturer, and the $\mathrm{pH}$ was adjusted to 7.2 using $0.165 \mathrm{M}$ MOPS and seeded with C. albicans. Briefly, a Candida biofilm was formed by adding $200 \mu \mathrm{L}$ of the suspension containing $5 \times 10^{5} \mathrm{CFU} / \mathrm{mL}$ to each well of the sterile 96-well microtiter plates and incubated at $37^{\circ} \mathrm{C}$ for $4 \mathrm{~h}$ (initial biofilm formation) and $24 \mathrm{~h}$ (mature biofilm) [56]. Then, the RPMI was removed, and the biofilms were washed twice with $200 \mu \mathrm{L}$ of phosphate buffer saline (PBS) $(10 \mathrm{mM}, \mathrm{pH}=7.4)$ to remove any 
non-adherent cells. The biofilms were then incubated with $\mathrm{CHD}$ at a concentration range of 160 to $0.63 \mu \mathrm{g} / \mathrm{mL}$ for two hours at $37^{\circ} \mathrm{C}$. Finally, the CHD was removed, and the biofilms were washed with $200 \mu \mathrm{L}$ of PBS.

\section{XTT Reduction Assay}

The XTT reduction assay measures biofilm viability based on cellular metabolic activity. It has been described in detail elsewhere [56]. Briefly, XTT was dissolved in PBS (pH $7.4)$ at $0.5 \mathrm{mg} / \mathrm{mL}$, and $10 \mu \mathrm{L}$ of menadione $(10 \mu \mathrm{M}$ in acetone) was added to $10 \mathrm{~mL}$ of XTT solution to facilitate the reduction of the tetrazolium to formazan. Then, $100 \mu \mathrm{L} \mathrm{of}$ XTT/menadione solution was added to each well, and the plate was incubated in the dark for two hours at $37^{\circ} \mathrm{C}$. Subsequently, $80 \mu \mathrm{L}$ aliquots were pipetted from the supernatant of each well into a new microtiter plate, and the absorbance was recorded at $\lambda_{450 \mathrm{~nm}}$ using a spectrophotometric plate reader (BioTec, EL800, Swindon, UK). Six replicates were tested.

\section{Candida Survival after Treatment}

Viable counting was used to determine the number of living cells, capable of reproduction after treatment with CHD. To each prewashed biofilm, a $100 \mu \mathrm{L}$ of MHB was added, and the biofilm was resuspended. The suspension was diluted and sub-cultured onto SDA plates, which were then incubated for $24-48 \mathrm{~h}$ at $30^{\circ} \mathrm{C}$. The viability was calculated as a percentage count of untreated biofilm. The test was performed in triplicate.

\subsubsection{Cytocompatibility}

\section{Cell Line and Culture Medium}

Human embryonic kidney cells (HEK293 cells) were used to test in vitro cytocompatibility. DMEM was supplemented with 10\% FBS, 1\% L-Glutamine solution (200 mM), and $1 \%$ Antibiotic-Antimycotic Solution.

\section{Cytocompatibility Assay}

HEK293 cells with a density of $4.0 \times 10^{4}$ cells were placed in each well of a 96-well microtiter plate, which was then incubated for $24 \mathrm{~h}$ at $37^{\circ} \mathrm{C}$ and humidified with $5 \% \mathrm{CO} 2$. The overnight cell culture medium was replaced with an increasing concentration of CHD in DMEM (1.25-160 $\mu \mathrm{g} / \mathrm{mL})$ and incubated for two hours. The supernatant was aspirated, and cell viability was evaluated using neutral red assay.

NR assay has been described in detail in an earlier study [26]. Briefly, $100 \mu \mathrm{L}$ of NR (80 mg/L in DMEM) was added to each well and the plate was incubated for two hours at $37^{\circ} \mathrm{C}$. The NR was removed, and the cells were washed in $150 \mu \mathrm{L}$ of PBS. This was followed by fixation with $100 \mu \mathrm{L}$ of $5 \%$ glutaraldehyde for $2 \mathrm{~min}$. Next, $150 \mu \mathrm{L}$ of de-stain solution (50\% absolute ethanol, $48 \%$ ultrapure water, and $2 \%$ glacial acetic acid) was added to each well, and the plate was left for $30 \mathrm{~min}$ on an orbital shaker to extract the NR from the cells. Finally, the optical density was measured at $\lambda_{540 \mathrm{n}} \mathrm{m}$ (Multiskan Ascent, Thermo Labsystems, Finland). Nine replicates were tested.

\subsubsection{Tablet Preparation}

CHD buccal tablets were prepared as shown in Table 1. CHD; HPMC; P407; and sorbitol, mannitol, or xylitol powders were blended for $15 \mathrm{~min}$ in a V-shaped powder blender (V-1, CapsulCN, China). The dosage of CHD was selected based on the results of antifungal effect and cytocompatibility testing, taking into account safe and effective concentrations.

\subsubsection{Powder Flow}

Flowability (Mass Flow)

The flow rates of the powder blends and granules were measured using an ERWEKA Granulate \& Powder Flow Tester (GTL, Regensburg, Germany). Approximately 12 g were 
placed in the hopper with an orifice of $10 \mathrm{~mm}$ in diameter. The results were displayed in $\mathrm{g} / \mathrm{sec}$. The test was performed in triplicate.

Compressibility Index

The bulk and the tapped volume of the powder blends and the granules were measured using a tapped density tester (TD 50-1000, Varian, UK). The tapped volumes were obtained by subjecting the powders to 200 taps each time until a constant volume was achieved.

Carr's compressibility index (CI) was calculated using the flowing equation:

$$
\text { Carr's Index }=\left(1-V_{t} / V_{0}\right)
$$

where $V_{0}$ is bulk volume, and $V_{t}$ is the tapped volume.

Measurements of mass flow and the calculation of the compressibility index were undertaken in triplicate.

\section{Melt Granulation}

The powder blend was placed in a beaker in a prewarmed water bath at $57^{\circ} \mathrm{C}$, which is equal to the melting point of $\mathrm{P} 407$, and mixed with a spatula for 1-3 min, then, sieved through a \#18 screen (Figure S1 Supplementary Materials).

\section{Tablet Pressing}

Magnesium stearate $0.5 \%$ was added to the granules and mixed for 3 min prior to being pressed. The granules were then pressed into $6 \mathrm{~mm}$ diameter tablets using a ZPS-8 mini rotary tablet machine (Shanghai Tianxiang and Chentai (STC) Pharmaceutical Machinery Co. Ltd., Shanghai, China).

\subsubsection{Characterisation of Buccal Tablets Friability}

The tablets were characterised for friability using a friability tester (Charles Ischi AG, AE-1, Derbyshire, UK).

\section{Tensile Strength}

The mechanical strength of the biconvex tablets was calculated using the following equation [57]:

$$
\sigma_{x}=10 \mathrm{~F} / \pi D^{2}[2.84 H / D-0.126 H / W+3.15 W / D+0.01]^{-1}
$$

where $\sigma_{x}$ is the tensile strength, $\mathrm{F}$ is breaking force (Newtons), $D$ is tablet diameter, $W$ is cylinger length, and $H$ is overall thickness of convex-faced disc, with all tablet dimensions in $\mathrm{mm}$.

The tablet breaking force or hardness was measured using a Varian VK 200, (UK) hardness tester $(n=10)$.

Swelling Index (SI)

A randomly selected tablet $\left(W_{0}\right)$ was weighted individually and adhered to a glass slide with a water droplet. The tablet was left for $30 \mathrm{~s}$ for the tablet to adhere and was then placed vertically in a beaker in a $37^{\circ} \mathrm{C}$ water bath (Clifton, Nickel-Electro Ltd., Bristol, UK). The slide was removed from the water bath and the excess water was dried carefully with a filter paper. The weight $\left(W_{s}\right)$ was recorded at 30, 60, 90, and $120 \mathrm{~min}$, and the SI was calculated using the equation below. Each tablet formulation was assessed in triplicate, and the results are expressed as the mean $\pm \mathrm{SD}$.

$$
S I=\left(W_{s}-W_{0}\right) / W_{0}
$$


where $W_{0}$ is the initial weight and $W_{s}$ is the final weight of the swollen tablet.

Determination of Ex Vivo Residence Time

Mucoadhesion was determined as a function of the residence time of the tablets in the oral cavity $[11,58]$. Chicken crop was used to test the mucoadhesion of the tablets. This is the dilated part of the oesophagus and is lined with a mucous membrane. It was cut into small pieces of approximately $1 \times 2 \mathrm{~cm}$, which were then fixed to a glass slide using cyanoacrylate glue. Each tablet was placed on top of the tissue and left for $30 \mathrm{~s}$ to start the adhesion process. The glass slide was then placed into the disintegration apparatus Varian VK 100, UK), prefilled with $37 \pm 0.2{ }^{\circ} \mathrm{C}$ of water [30]. The test was performed for $120 \mathrm{~min}$ at $50 \mathrm{rpm}$, and samples were examined every $15 \mathrm{~min}$. Each tablet formulation was assessed in triplicate.

\subsubsection{In Vitro Dissolution of CHD (Apparatus 1)}

The dissolution was performed using Apparatus type 1 (basket method, Varian 705 DS BP Dissolution, Varian, UK). One tablet was placed in $500 \mathrm{~mL}$ of water at $37^{\circ} \mathrm{C}$ and a rotating speed of $50 \mathrm{rpm}$. A volume of $4 \mathrm{~mL}$ was withdrawn at predetermined time intervals. The concentration of CHD was determined spectrophotometrically at $\lambda_{254 \mathrm{~nm}}$ (Biochrom WPA Biowave II UV-Spectrophotometry, UK). The test was performed in triplicate.

\subsubsection{In Vitro Dissolution Using a Controlled Flow Rate (CFR)}

The dissolution was performed under a constant flow rate of $1 \mathrm{~mL} / \mathrm{min}$ for two hours. The normal salivary flow rate is $\geq 1 \mathrm{~mL} / \mathrm{min}$ with a maximum value of $7 \mathrm{~mL} / \mathrm{min}$ [21,22]. The aim of this investigation was to mimic the salivary flow rate in the oral cavity. Figure 6 illustrates the set-up of the CFR method. Water was placed in a Schott bottle inside a water bath set at $37^{\circ} \mathrm{C}$. The flow rate of the water was controlled using a peristaltic pump at $1 \mathrm{~mL} / \mathrm{min}$. A pre-weighed tablet was adhered using one drop of water to a pre-weighed sample holder (the head of a plastic Pasteur pipette, cut into two pieces) and placed in a beaker in the water bath. Samples were collected with a syringe every $10 \mathrm{~min}$ for two hours and measured using a UV-VIS spectrophotometer at $\lambda_{254} \mathrm{~nm}$. The drug release was recorded for each time point, and the cumulative drug release was calculated by adding the percentage of drug release to the previous time point(s). The test was performed in triplicate.

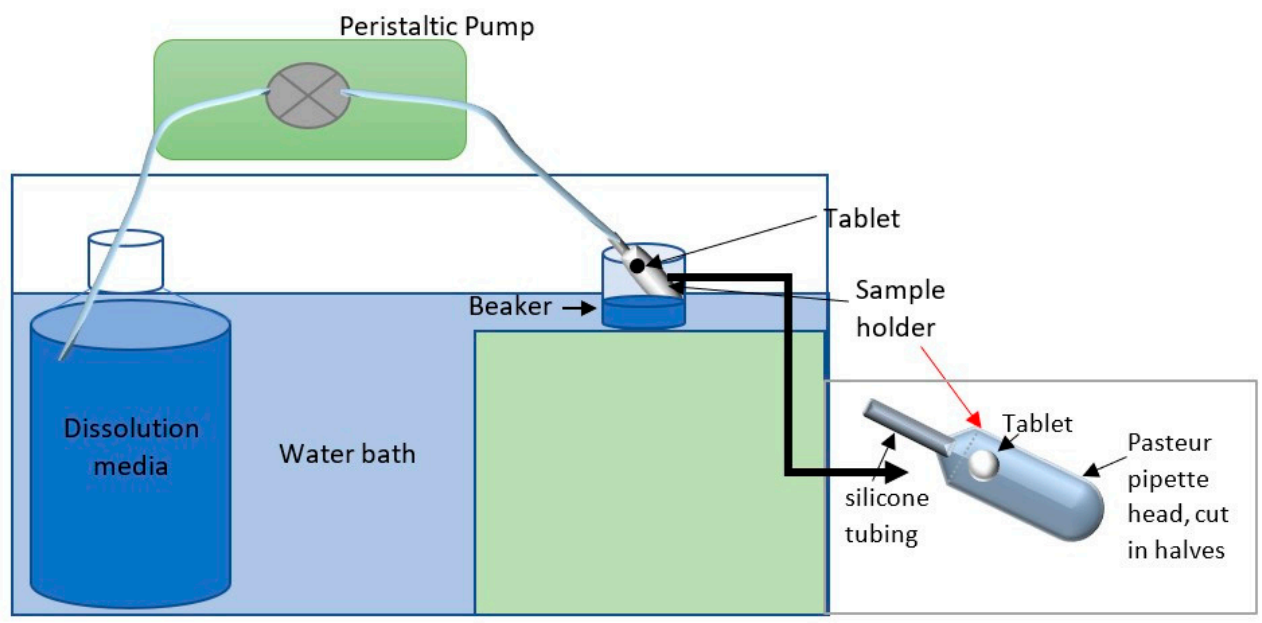

Figure 6. Diagram illustrating the setup of the CFR method. 


\subsubsection{Tablet Erosion E\%}

Tablet erosion was investigated to measure the weight of the dried tablet after CRF dissolution. Tablet residues were dried in the oven at $37^{\circ} \mathrm{C}$ for $24-48 \mathrm{~h}$, and the percentage erosion $(E \%)$ was calculated using the following equation.

$$
E \%=\left(W_{0}-W_{e}\right) / W_{0} \times 100
$$

where $W_{0}$ is the initial weight of the tablet, and We is the dried weight of the tablet after swelling or dissolution.

\subsubsection{Dissolution Efficiency (DE\%)}

$\mathrm{DE} \%$ is determined from the percentile ratio of the area under the curve (AUC) of the dissolution data to the AUC of $100 \%$ release between time zero to the end of dissolution [59]. It was obtained using the equation below. OriginPro 2017 software was used to calculate the area under the curve.

$$
\text { D.E. }=\frac{\int_{0}^{t} y \times d t}{y_{100} \times t} \times 100 \%
$$

where $t$ is the time, $y$ is the percentage of drug dissolved at time $t$, and $\int_{0}^{t} y \times d t$ is the area under the curve.

\subsubsection{Kinetics of Drug Release}

The kinetics of drug release was investigated using zero order (where drug release was at a constant rate), first order (where drug release was concentration-dependant and was proportional to the amount of drug in the matrix), Higuchi (where drug release was difusion-controlled), Hixon-Crowell, Korsmeyer-Peppas models or the power law (where drug release was attributed to diffusion, swelling and erosion, or polymer relaxation), and the Hopfenberg model (where drug release was erosion-controlled) [60]. The latter is an empirical model used to describe drug release from erodible matrices (see the Supplementary Materials). Non-linear fitting for all models was performed using DDsolver, which is an add-in program for Microsoft Excel [51]. To select the best fitting model, both the coefficient of determination $\mathrm{R}^{2}$ and the model selection criterion (MSC) were obtained using DDsolver.

\subsubsection{Fourier Transform Infrared Spectroscopy (FTIR) and Differential Scanning Calorimetry (DSC)}

FTIR and DSC were used to investigate the possibility of interaction between the polymers and the drug. CHD, HPMC, P407, S4, M4, and X4 physical mix, granules, and tablets were investigated. FTIR Spectra were obtained using a Bruker Alpha spectrometer (Germany). Samples were scanned from 4000 to $400 \mathrm{~cm}^{-1}$. For DSC, a sample size of $5.0 \pm 0.2 \mathrm{mg}$ was heated from 25 to $300{ }^{\circ} \mathrm{C}$ in an aluminum pan under a nitrogen flow of $40 \mathrm{~mL} / \mathrm{min}$ at a scan rate of $10^{\circ} \mathrm{C} / \mathrm{min}$. The analysis was performed using Mettler Toledo DSC823e (Switzerland).

\subsubsection{Statistical Analysis}

The statistical differences were determined using the student's unpaired $t$-test (Welch's), the paired t-test using Grappad Prism 9.1.0. $p<0.05$ was considered to be statistically significant.

\section{Conclusions}

The exposure of the human cell line HEK293 to a concentration of $20 \mu \mathrm{g} / \mathrm{mL}$ of chlorhexidine for two hours showed no cytotoxic effect and a promising antifungal activity against $C$. albicans biofilms with complete killing of planktonic cells. This concentration was utilized to prepare mucoadhesive buccal tables for targeted buccal drug delivery. CHD is 
not absorbed from the GIT, and consequently, it has no systemic side effects or drug-drug interaction. Melt granulation showed a remarkable improvement in powder flow, and no interaction was observed between CHD and the excipients. The CFR method was used to mimic drug release in the oral cavity from saliva. The formulations S4, M4, and X4 showed zero order and erosion-based drug release. They can be considered suitable candidates for the treatment of OPC. The formulations can be further investigated for different drugs, trans-buccal, and oral systemic sustained release formulations.

Supplementary Materials: The following are available online at https:/ / www.mdpi.com/article/10 .3390/ph14060493/s1, Figure S1: Melt Granules, Figure S2: Swelling index, Figure S3: SEM images, Figure S4: FTIR Spectra, Figure S5: DSC thermograms. Table S1: DSC Melting peaks obtained, Table S2: Drug release kinetics data. References [61] is cited in the supplementary materials.

Author Contributions: Conceptualization, E.A.-A.; methodology, E.A.-A. and D.H.; validation, E.A.-A. and K.D.; formal analysis, E.A.-A.; investigation, E.A.-A.; resources, E.A.-A. and K.D.; data curation, E.A.-A. and K.D.; writing—original draft preparation, E.A.-A.; writing—review and editing, E.A.-A. and K.D.; visualization, E.A.-A.; supervision, D.H. All authors have read and agreed to the published version of the manuscript.

Funding: This research received no external funding.

Institutional Review Board Statement: Not Applicable.

Informed Consent Statement: Not Applicable.

Data Availability Statement: Not Applicable.

Conflicts of Interest: The authors declare no conflict of interest.

\section{References}

1. Arendrup, M.C.; Patterson, T.F. Multidrug-Resistant Candida: Epidemiology, Molecular Mechanisms, and Treatment. J. Infect. Dis. 2017, 216, S445-S451. [CrossRef]

2. He, J.; Thomas, M.A.; De Anda, J.; Lee, M.W.; Van Why, E.; Simpson, P.; Wong, G.C.L.; Grayson, M.H.; Volkman, B.F.; Huppler, A.R. Chemokine CCL28 Is a Potent Therapeutic Agent for Oropharyngeal Candidiasis. Antimicrob. Agents Chemother. 2020, 64. [CrossRef] [PubMed]

3. Pappas, P.G.; Kauffman, C.A.; Andes, D.R.; Clancy, C.J.; Marr, K.A.; Ostrosky-Zeichner, L.; Reboli, A.C.; Schuster, M.G.; Vazquez, J.A.; Walsh, T.J.; et al. Clinical Practice Guideline for the Management of Candidiasis: 2016 Update by the Infectious Diseases Society of America. Clin. Infect. Dis. 2016, 62, e1-e50. [CrossRef] [PubMed]

4. Girois, S.B.; Chapuis, F.; Decullier, E.; Revol, B.G.P. Erratum: Adverse effects of antifungal therapies in invasive fungal infections: Review and meta-analysis. Eur. J. Clin. Microbiol. Infect. Dis. 2006, 25, 138-149. [CrossRef] [PubMed]

5. Billaud, E.M.; Guillemain, R.; Berge, M.; Amrein, C.; Lefeuvre, S.; Louët, A.L.-L.; Boussaud, V.; Chevalier, P. Pharmacological considerations for azole antifungal drug management in cystic fibrosis lung transplant patients. Med. Mycol. 2010, 48, 52-59. [CrossRef]

6. Morschhäuser, J. The genetic basis of fluconazole resistance development in Candida albicans. Biochim. Biophys. Acta (BBA) Mol. Basis Dis. 2002, 1587, 240-248. [CrossRef]

7. Kartsonis, N.A.; Saah, A.; Lipka, C.J.; Taylor, A.; Sable, C.A. Second-line therapy with caspofungin for mucosal or invasive candidiasis: Results from the caspofungin compassionate-use study. J. Antimicrob. Chemother. 2004, 53, 878-881. [CrossRef] [PubMed]

8. Campoy, S.; Adrio, J.L. Antifungals. Biochem. Pharmacol. 2017, 133, 86-96. [CrossRef] [PubMed]

9. DeGregorio, M.W.; Lee, W.M.F.; Ries, C.A. Candida infections in patients with acute leukemia: Ineffectiveness of nystatin prophylaxis and relationship between oropharyngeal and systemic candidiasis. Cancer 1982, 50, 2780-2784. [CrossRef]

10. Rençber, S.; Karavana, S.Y.; Yilmaz, F.F.; Eraç, B.; Nenni, M.; Gurer-Orhan, H.; Limoncu, M.H.; Güneri, P.; Ertan, G. Formulation and evaluation of fluconazole loaded oral strips for local treatment of oral candidiasis. J. Drug Deliv. Sci. Technol. 2019, 49, 615-621. [CrossRef]

11. Nafee, N.A.; Ismail, F.A.; Boraie, N.A.; Mortada, L.M. Mucoadhesive buccal patches of miconazole nitrate: In vitro/in vivo performance and effect of ageing. Int. J. Pharm. 2003, 264, 1-14. [CrossRef]

12. Roy, S.; Pal, K.; Anis, A.; Pramanik, K.; Prabhakar, B. Polymers in Mucoadhesive Drug-Delivery Systems: A Brief Note. Des. Monomers Polym. 2009, 12, 483-495. [CrossRef]

13. Tejada, G.; Barrera, M.G.; Piccirilli, G.N.; Sortino, M.; Frattini, A.; Salomón, C.J.; Lamas, M.C.; Leonardi, D. Development and Evaluation of Buccal Films Based on Chitosan for the Potential Treatment of Oral Candidiasis. AAPS PharmSciTech 2017, 18, 936-946. [CrossRef] [PubMed] 
14. Ceschel, G.C.; Bergamante, V.; Calabrese, V.; Biserni, S.; Ronchi, C.; Fini, A. Design and Evaluation In Vitro of Controlled Release Mucoadhesive Tablets Containing Chlorhexidine. Drug Dev. Ind. Pharm. 2006, 32, 53-61. [CrossRef]

15. Juliano, C.C.A.; Cossu, M.; Pigozzi, P.; Rassu, G.; Giunchedi, P. Preparation, In Vitro Characterization and Preliminary In Vivo Evaluation of Buccal Polymeric Films Containing Chlorhexidine. AAPS PharmSciTech 2008, 9, 1153-1158. [CrossRef]

16. Park, J.-B.; Prodduturi, S.; Morott, J.; I Kulkarni, V.; Jacob, M.R.; I Khan, S.; Stodghill, S.P.; A Repka, M. Development of an antifungal denture adhesive film for oral candidiasis utilizing hot melt extrusion technology. Expert Opin. Drug Deliv. 2015, 12, 1-13. [CrossRef]

17. Epstein, J.; Ransier, A.; Lunn, R.; Spinelli, J. Enhancing the effect of oral hygiene with the use of a foam brush with chlorhexidine. Oral Surg. Oral Med. Oral Pathol. 1994, 77, 242-247. [CrossRef]

18. Reitzel, R.A.; Rosenblatt, J.; Gerges, B.Z.; Jarjour, A.; Fernández-Cruz, A.; Raad, I.I. The potential for developing new antimicrobial resistance from the use of medical devices containing chlorhexidine, minocycline, rifampicin and their combinations: A systematic review. JAC Antimicrob. Resist. 2020, 2, dlaa002. [CrossRef]

19. Williams, D.; Kuriyama, T.; Silva, S.; Malic, S.; Lewis, M.A.O. Candida biofilms and oral candidosis: Treatment and prevention. Periodontology 2000 2010, 55, 250-265. [CrossRef]

20. Dinsmore, W.W.; Wyllie, M.G. The long-term efficacy and safety of a testosterone mucoadhesive buccal tablet in testosteronedeficient men. BJU Int. 2012, 110, 162-169. [CrossRef]

21. Humphrey, S.P.; Williamson, R.T. A review of saliva: Normal composition, flow, and function. J. Prosthet. Dent. 2001, 85, 162-169. [CrossRef]

22. Mulic, A.; Tveit, A.B.; Songe, D.; Sivertsen, H.; Skaare, A.B. Dental erosive wear and salivary flow rate in physically active young adults. BMC Oral Health 2012, 12, 8. [CrossRef] [PubMed]

23. Suci, P.A.; Tyler, B.J. Action of Chlorhexidine Digluconate against Yeast and Filamentous Forms in an Early-Stage Candida albicans Biofilm. Antimicrob. Agents Chemother. 2002, 46, 3522-3531. [CrossRef]

24. Chandra, J.; Mukherjee, P.; Leidich, S.; Faddoul, F.; Hoyer, L.; Douglas, L.; Ghannoum, M. Antifungal Resistance of Candidal Biofilms Formed on Denture Acrylic in vitro. J. Dent. Res. 2001, 80, 903-908. [CrossRef] [PubMed]

25. Khot, P.D.; Suci, P.A.; Tyler, B.J. Candida albicans viability after exposure to amphotericin B: Assessment using metabolic assays and colony forming units. J. Microbiol. Methods 2008, 72, 268-274. [CrossRef]

26. Repetto, G.; Del Peso, A.; Zurita, J.L. Neutral red uptake assay for the estimation of cell viability/cytotoxicity. Nat. Protoc. 2008, 3, 1125-1131. [CrossRef] [PubMed]

27. Doktorovova, S.; Souto, E.B.; Silva, A.M. Nanotoxicology applied to solid lipid nanoparticles and nanostructured lipid carriers-A systematic review of in vitro data. Eur. J. Pharm. Biopharm. 2014, 87, 1-18. [CrossRef]

28. Peppas, N. Hydrogels in pharmaceutical formulations. Eur. J. Pharm. Biopharm. 2000, 50, 27-46. [CrossRef]

29. Caló, E.; Khutoryanskiy, V.V. Biomedical applications of hydrogels: A review of patents and commercial products. Eur. Polym. J. 2015, 65, 252-267. [CrossRef]

30. Al-Ani, E.; Martin, C.; Britland, S.T.; Doudin, K.; Hill, D.J. The effect of the source and the concentration of polymers on the release of chlorhexidine from mucoadhesive buccal tablets. Saudi Pharm. J. 2019, 27, 756-766. [CrossRef]

31. Sudhakar, Y.; Kuotsu, K.; Bandyopadhyay, A. Buccal bioadhesive drug delivery-A promising option for orally less efficient drugs. J. Control Release 2006, 114, 15-40. [CrossRef]

32. Ruel-Gariépy, E.; Leroux, J.-C. In situ-forming hydrogels-review of temperature-sensitive systems. Eur. J. Pharm. Biopharm. 2004, 58, 409-426. [CrossRef] [PubMed]

33. Dumortier, G.; Grossiord, J.L.; Agnely, F.; Chaumeil, J.C. A Review of Poloxamer 407 Pharmaceutical and Pharmacological Characteristics. Pharm. Res. 2006, 23, 2709-2728. [CrossRef] [PubMed]

34. Sakeer, K.; Al-Zein, H.; Hassan, I.; Desai, S.; Nokhodchi, A. Enhancement of dissolution of nystatin from buccoadhesive tablets containing various surfactants and a solid dispersion formulation. Arch. Pharmacal Res. 2010, 33, 1771-1779. [CrossRef]

35. Matanović, M.R.; Kristl, J.; Grabnar, P.A. Thermoresponsive polymers: Insights into decisive hydrogel characteristics, mechanisms of gelation, and promising biomedical applications. Int. J. Pharm. 2014, 472, 262-275. [CrossRef] [PubMed]

36. Bolhuis, G.K.; Rexwinkel, E.G.; Zuurman, K. Polyols as filler-binders for disintegrating tablets prepared by direct compaction. Drug Dev. Ind. Pharm. 2009, 35, 671-677. [CrossRef] [PubMed]

37. Femiano, F.; Rullo, R.; Di Spirito, F.; Lanza, A.; Festa, V.M.; Cirillo, N. A comparison of salivary substitutes versus a natural sialogogue (citric acid) in patients complaining of dry mouth as an adverse drug reaction: A clinical, randomized controlled study. Oral Surg. Oral Med. Oral Pathol. Oral Radiol. Endodontol. 2011, 112, e15-e20. [CrossRef]

38. Gliemmo, M.; Campos, C.; Gerschenson, L. Effect of Sweet Humectants on Stability and Antimicrobial Action of Sorbates. J. Food Sci. 2004, 69, fms39-fms44. [CrossRef]

39. Chaturvedi, K.; Gajera, B.Y.; Xu, T.; Shah, H.; Dave, R.H. Influence of processing methods on physico-mechanical properties of Ibuprofen/HPC-SSL formulation. Pharm. Dev. Technol. 2018, 23, 1108-1116. [CrossRef]

40. Stoltenberg, I.; Breitkreutz, J. Orally disintegrating mini-tablets (ODMTs)-A novel solid oral dosage form for paediatric use. Eur. J. Pharm. Biopharm. 2011, 78, 462-469. [CrossRef]

41. Jamzad, S.; Tutunji, L.; Fassihi, R. Analysis of macromolecular changes and drug release from hydrophilic matrix systems. Int. J. Pharm. 2005, 292, 75-85. [CrossRef] 
42. Chun, M.-K.; Kwak, B.-T.; Choi, H.-K. Preparation of buccal patch composed of carbopol, poloxamer and hydroxypropyl methylcellulose. Arch. Pharmacal Res. 2003, 26, 973-978. [CrossRef]

43. Salamat-Miller, N.; Chittchang, M.; Johnston, T.P. The use of mucoadhesive polymers in buccal drug delivery. Adv. Drug Deliv. Rev. 2005, 57, 1666-1691. [CrossRef]

44. Giannola, L.I.; De Caro, V.; Giandalia, G.; Siragusa, M.G.; Tripodo, C.; Florena, A.M.; Campisi, G. Release of naltrexone on buccal mucosa: Permeation studies, histological aspects and matrix system design. Eur. J. Pharm. Biopharm. 2007, 67, 425-433. [CrossRef]

45. De Caro, V.; Scaturro, A.L.; Di Prima, G.; Avellone, G.; Sutera, F.M.; Di Fede, O.; Campisi, G.; Giannola, L.I. Aloin delivery on buccal mucosa:ex vivostudies and design of a new locoregional dosing system. Drug Dev. Ind. Pharm. 2015, 41, 1541-1547. [CrossRef] [PubMed]

46. Di Prima, G.; Campisi, G.; De Caro, V. Amorphous Ropinirole-Loaded Mucoadhesive Buccal Film: A Potential Patient-Friendly Tool to Improve Drug Pharmacokinetic Profile and Effectiveness. J. Pers. Med. 2020, 10, 242. [CrossRef]

47. De Caro, V.; Ajovalasit, A.; Sutera, F.M.; Murgia, D.; Sabatino, M.A.; Dispenza, C. Development and Characterization of an Amorphous Solid Dispersion of Furosemide in the Form of a Sublingual Bioadhesive Film to Enhance Bioavailability. Pharmaceutics 2017, 9, 22. [CrossRef] [PubMed]

48. Levina, M.; Rajabi-Siahboomi, A.R. The Influence of Excipients on Drug Release from Hydroxypropyl Methylcellulose Matrices. J. Pharm. Sci. 2004, 93, 2746-2754. [CrossRef]

49. Williams, R.O., 3rd; Reynolds, T.D.; Cabelka, T.D.; Sykora, M.A.; Mahaguna, V. Investigation of Excipient Type and Level on Drug Release from Controlled Release Tablets Containing HPMC. Pharm. Dev. Technol. 2002, 7, 181-193. [CrossRef]

50. Cheng, Y.; Qin, H.; Acevedo, N.C.; Jiang, X.; Shi, X. 3D printing of extended-release tablets of theophylline using hydroxypropyl methylcellulose (HPMC) hydrogels. Int. J. Pharm. 2020, 591, 119983. [CrossRef] [PubMed]

51. Zhang, Y.; Huo, M.; Zhou, J.; Zou, A.; Li, W.; Yao, C.; Xie, S. DDSolver: An Add-In Program for Modeling and Comparison of Drug Dissolution Profiles. AAPS J. 2010, 12, 263-271. [CrossRef] [PubMed]

52. Peppas, N.A.; Sahlin, J.J. A simple equation for the description of solute release. III. Coupling of diffusion and relaxation. Int. J. Pharm. 1989, 57, 169-172. [CrossRef]

53. Sriamornsak, P.; Thirawong, N.; Weerapol, Y.; Nunthanid, J.; Sungthongjeen, S. Swelling and erosion of pectin matrix tablets and their impact on drug release behavior. Eur. J. Pharm. Biopharm. 2007, 67, 211-219. [CrossRef] [PubMed]

54. Karasulu, H.Y. Modeling of theophylline release from different geometrical erodible tablets. Eur. J. Pharm. Biopharm. 2000, 49, 177-182. [CrossRef]

55. Katzhendler, I.; Hoffman, A.; Goldberger, A.; Friedman, M. Modeling of Drug Release from Erodible Tablets. J. Pharm. Sci. 1997, 86, 110-115. [CrossRef]

56. Pierce, C.G.; Uppuluri, P.; Tristan, A.R.; Wormley, F.L., Jr.; Mowat, E.; Ramage, G.; Lopez-Ribot, J.L. A simple and reproducible 96-well plate-based method for the formation of fungal biofilms and its application to antifungal susceptibility testing. Nat. Protoc. 2008, 3, 1494-1500. [CrossRef]

57. Pitt, K.G.; Newton, J.M.; Stanley, P. Tensile fracture of doubly-convex cylindrical discs under diametral loading. J. Mater. Sci. 1988, 23, 2723-2728. [CrossRef]

58. Nakamura, F. In vitro and in vivo nasal mucoadhesion of some water-soluble polymers. Int. J. Pharm. 1996, 134, $173-181$. [CrossRef]

59. Anderson, N.; Bauer, M.; Boussac, N.; Khan-Malek, R.; Munden, P.; Sardaro, M. An evaluation of fit factors and dissolution efficiency for the comparison of in vitro dissolution profiles. J. Pharm. Biomed. Anal. 1998, 17, 811-822. [CrossRef]

60. Costa, P.; Lobo, J.M.S. Modeling and comparison of dissolution profiles. Eur. J. Pharm. Sci. 2001, 13, 123-133. [CrossRef]

61. Beck-Broichsitter, M.; Bohr, A.; Ruge, C.A. Poloxamer-Decorated Polymer Nanoparticles for Lung Surfactant Compatibility. Mol. Pharm. 2017, 14, 3464-3472. [CrossRef] [PubMed] 